\title{
O Design de Produto como Ferramenta para o Empoderamento Feminino
}

Amanda de Sousa Roque;

Bruno Montanari Razza

resumo:

O presente trabalho pretende estudar como o Design de Produto pode contribuir para o Empoderamento Feminino, verificando os conceitos de empoderamento e sua relação com o design, a importância das mulheres exercerem sua cidadania plena nos dias atuais e discutir o papel do design como agente social. Este estudo também evidencia como o design se relaciona com o mercado consumidor feminino, e quais as preocupações que o projetista costuma ter em mente ao criar um produto para o público feminino. A fim de evidenciar a relação entre design e empoderamento feminino e mostrar que é possível criar um produto empoderador, foram analisados alguns estudos de caso, que revelam que o design de produto pode ser uma ferramenta social muito importante para 0 desenvolvimento social que o empoderamento feminino traz consigo.

palavras-chave:

Design; Produtos; Empoderamento; Feminismo; Consumo 


\section{Introdução}

As mulheres são constantemente referidas como uma "categoria" de ser humano, sendo elas posta abaixo do ser que denominam "homem", sendo assim, o comportamento exigido dessa categoria, seja a maneira de falar, de sentar, de comer, é imposto para todos seres pensantes que nascem do sexo feminino (BEAUVOIR, 2015). Segundo Simone Beauvoir (2015), a mulher e o homem nunca partilharam de condições iguais. Entretanto, a evolução da sociedade fez com que a mulher tenha ganhado mais voz e espaço, porém, ela ainda arca com uma grande desvantagem frente ao homem, desvantagem essa que ainda afeta as estruturas sociais e econômicas.

O feminismo é o movimento que, segundo Maria de Lourdes Pintasilgo (1981, p.14) é marcado pela "luta das mulheres por sua Auto-determinação; é o processo de libertação de uma cultura subjugada; é a conquista do espaço social e político onde ser mulher tenha lugar." Seguindo essa definição breve, é possível perceber a importância da luta feminista na sociedade, como ela coopera para a evolução e emancipação da mulher como o ser social e digno de respeito e admiração que é.

A luta feminista pode ser dividida em três "ondas", que são caracterizadas por cada período de tempo, objetivos e conquistas desejadas e obtidas pelas mulheres através de sua dedicação para com o movimento e outras mulheres. Compreender que cada uma das fases da luta feminista fez parte da construção do conceito de empoderamento feminino é fundamental para notar como tudo é relacionado, sendo o empoderamento da mulher o foco principal de toda sua jornada, visto a necessidade da mulher ser compreendida de forma dissociada do gênero e homem, como ser único, pensante e autônomo que é.

Entender como o empoderamento feminino é obtido e quais seus benefícios para a sociedade, é aceitar que os direitos da mulher vão muito além da participação política dela e conscientização de seu espaço real na sociedade (STROMQUIST, 1997). Sendo assim, o designer, como o ser social, tem de estar muito aberto a informações novas e aos estudos feministas e de empoderamento, tendo ele o dever de ter conhecimento sobre essa luta e emancipação, e ter isso em mente e consideração quando projetista para os dias atuais.

A conexão do Design e o empoderamento pode ser melhor apreendida quando é entendido que todo design é social, como afirmam Silva e Neves (2005). Sendo assim, para projetar algo, o designer tem que estar muito atento as consequências sociais desse projeto, para tanto, é imprescindível que o designer tenha muita consciência dos valores que associa a seus produtos e serviços e como eles podem modificar a sociedade e torna-la melhor.

O Design teve grandes evoluções desde os séculos passados, e um de seus grandes benefícios é o desenvolvimento contínuo e seu grande contributo para o avanço da sociedade. Nesse trabalho analisaremos se o design de produto tem alcançado a evolução e emancipação da mulher nos últimos anos e como ele pode se tornar mais empoderador e libertador das mulheres.

\section{A importância de Mulheres Empoderadas}

As lutas feministas trouxeram consigo novas perspectivas para as mulheres, sendo o empoderamento feminino uma questão a ainda ser alcançada de forma plena. Desde a primeira onda do feminismo, as mulheres lutam por seus valores e direitos, reivindicando seu espaço na política, educação e como sujeito completo e independente que são.

A segunda onda do feminismo trouxe consigo o conceito de Empoderamento Feminino, sendo que o termo empoderamento surgiu na década de 60, referindo-se as lutas pelos direitos civis dos afroamericanos nos Estados Unidos da América (STROMQUIST, 1997). O movimento feminista começou a utilizar o termo na década de 70, aplicando-o no âmbito de gênero, com o propósito de inserir de forma mais ativa as mulheres na esfera política, tanto pública quanto privada (STROMQUIST, 1997).

A definição da palavra empoderamento é muito importante para a compreensão da relevância das mulheres no espaço público e seu processo de emancipação (CRUZ, 2018). A autora Nelly Stromquist (1997) tem uma visão mais complexa e instrutiva, considerando empoderamento um conceito sociopolítico que vai além da participação política e conscientização. Sendo assim, para a autora, para uma apreensão correta do termo é necessário analisar componentes cognitivos, psicológicos, políticos e econômicos. Stromquist (1997) interpreta que o empoderamento feminino é 
um processo e, para ele ser alcançado, é necessário que a mulher compreenda sobre sua subordinação e as causas e efeitos dela na sociedade (Componente Cognitivo); inclua seus sentimentos para uma melhora de suas condições na sociedade, sendo a autoconfiança e autoestima fundamentais (Componente Psicológico); ter capacidade de promover e organizar mudanças na sociedade admitindo suas capacidades de analisar o meio de modo político e social (Componente Político); e finalmente conquistar sua independência financeira (Componente Econômico).

Para finalizar sua concepção de empoderamento feminino, Stromquist (1997) definiu que para a mulher conquistar seu sentimento de independência, é necessário que saia de casa e envolva-se em projetos, principalmente em atividades em grupo, sendo a atividade em si indiferente, desde que ela fomente a autoestima, competência e autonomia da mulher.

O empoderamento feminino tem importância para o desenvolvimento social e, segundo a UNICEF (1997) há cinco níveis a serem alcançados para que haja a igualdade de gênero, sendo o empoderamento necessário em todo o processo acerca de cada nível. À vista disso, o órgão das Nações Unidas prevê que os níveis são compostos por:

- Bem-estar, focado no bem-estar material das mulheres no que refere-se à oferta de comida, renda e trabalho;

- Acesso, prevê o acesso da figura feminina à recursos básicos como terra, crédito, trabalho e educação;

- Conscientização, presume que a mulher tenha consciência da desigualdade à qual está sujeita $\mathrm{e}$ se conscientize sobre essas crenças e práticas, rejeitando essa subordinação como ordem natural que foi imposta por um sistema patriarcal discriminatório;

- Participação, pressupõe uma participação mais ativa da figura feminina em decisões importantes em diferentes setores e cargos;

- Controle, esse nível em questão consegue unir todos os outros em um círculo interconectado.

Quanto maior o Controle e Participação feminina nas decisões, maior o desenvolvimento e obtenção de poder, fazendo com que essa participação garanta o maior domínio sobre fatores de produção e acesso igual às mulheres, permitindo também às mulheres um maior acesso aos recursos e tornando possível o bem-estar mencionado.

Seguindo o pensamento da organização UNICEF, Stromquist (1997) alega que promover o empoderamento feminino é uma necessidade, sendo uma forma de modificar a distribuição desigual de poder nas relações interpessoais, sociedade e instituições. É possível notar que o empoderamento gera mudanças e conscientização na sociedade, enfrentando estruturas fixas e antiquadas que tendem a reconhecerem a mulher apenas no âmbito do lar e da família.

\section{Design como Agente Social}

$\mathrm{O}$ design carrega consigo uma carga social muito forte, visto que gera produtos, físicos ou digitais, e serviços que irão interagir diretamente com as pessoas e o meio ao qual está inserido, causando diversos impactos na sociedade e ambiente. Para tanto, é importante que o designer, quando projetista, tenha muita consciência dos valores que atribui a seus produtos, pois eles podem ajudar o dia a dia das pessoas e o meio ambiente, ou acelerar o processo de degradação do ambiente e dificultar a interação usuário-produto, causando desconforto físico e mental.

A concepção popular de design segundo Fornasier, Martins e Merino (2012), está muito ligada a criação de produtos de beleza e luxo, o que é equívoco e indesejado, visto que "camufla a função primeira do designer que é facilitar o cumprimento de tarefas e necessidades básicas do homem, por meio da criação de produtos, mensagens ou serviços" (FORNAZIER et al. 2012, p. 4).

É difícil desassociar o que é Design e como ele pode ser Social, visto que não há um produto do design que não interaja com as pessoas e o meio (WANDERLEY et al., 2017). O designer tem que ter constante atenção aos determinantes culturais, nas definições de identidades e nas transformações de dados, tendo um comprometimento moral com a sociedade ao gerar informações válidas e significativas, que serão expostas em seus produtos.

Silva e Neves (2005) entendem que os produtos de design só podem ser percebidos dentro de um contexto social, onde questões econômicas, políticas, tecnológicas e culturais também são importantes para o desenvolvimento do produto. 
Para Niemeyer (2017), qualquer produto de design tem repercussão social, visto que ele necessita de matéria prima e energia, que acarretam um efeito ambiental, sendo ele produzido por pessoas e comprado por outras pessoas a fim de satisfazer suas necessidades através da função que desempenham, além de movimentar a economia. A autora ainda acredita que o design seja capaz de gerar uma intervenção positiva na sociedade, sendo o resultado do projeto de design capaz de "beneficiar e capacitar membros de comunidades desassistidas para que desfrutem de uma posição social digna, com possibilidade de atuar em diversos setores econômicos" (NIEMEYER, 2017, p. 75).

Safar e Almeida (2014) acreditam que o designer tem responsabilidade social visto que é responsável por reproduzir valores etéreos por meio de linguagem visual que é apresentada nos produtos. Assim, o impacto do designer pode ter grandes ou pequenas proporções na sociedade, mas o fato é que seus produtos ou serviços sempre trazem consequências. As autoras, ao analisarem o design de produto e sua relação com as mulheres acreditam que atualmente haja "despreparo dos designers para compreender os códigos culturais estabelecidos entre os gêneros, limitando-se à criação com base em estereótipos culturais". Sendo assim, o designer tem um dever para com a sociedade de não se limitar a estereótipos ou conhecimentos superficiais, visto que o impacto do produto criado pelo designer terá um alcance inestimável e pode propagar tanto novos conhecimentos e ajudar á evolução e bem estar, quanto trazer uma recessão de pensamentos e ideias.

\section{Design e o Mercado de Consumo Feminino}

A independência financeira que a mulher adquiriu durante as últimas décadas e o grande aumento do poder econômico dela tem como consequência o maior consumo desse grupo que por muitos anos foi esquecido pelos designers.

As mulheres conquistaram seu espaço nas universidades e hoje somam mais da metade dos universitários do mundo (cerca de 51\%) segundo dados da ONU (2010). Esse aumento da figura feminina nas cadeiras universitárias é um dos principais motivos de sua emancipação, visto que estão mais inseridas no mercado de trabalho e vêm ganhando cada dia mais espaço graças à formação (PORTAL BRASIL, 2016).

Proporcionalmente ao crescimento da qualificação feminina, houve o aumento do seu poder de compra e reconhecimento como a consumidora assídua que é. Assim, a exigência das mulheres como compradoras também aumentou consideravelmente, elas deixaram de aceitar produtos que são pouco pensados e maioritariamente são desenvolvidos para uso doméstico e familiar, para se importarem com a qualidade e praticidade daquilo que compram, sempre visando a melhoria que o produto trará em suas vidas (JOHNSON; LEARNED, 2005).

Responsáveis por mais de $85 \%$ da opinião final na compra de produtos, as mulheres vêm dominando o mercado consumidor (WOMEN CHOICE AWARD, 2018). Segundo a pesquisa feita por Johnson e Learned no começo dos anos 2000, 8 em cada 10 cheques pessoais nos Estados Unidos da América (EUA), uma das maiores potências de consumo do mundo, são assinados por mulheres, sendo elas também responsáveis pelos gastos do salário dos parceiros (JOHNSON e LEARNED, 2005). Esse estudo, embora seja antigo, mostra uma realidade que começava há alguns anos, sendo que hoje essa perspectiva da mulher como a maior consumidora é inegável, tendo as empresas o dever de olhar para as reais necessidades do público feminino, a fim de conseguirem aumentar vendas e lucros.

A designer Yvonne Lin, fez um pequeno ensaio sobre o mercado consumidor feminino, analisando algumas questões quanto a importância de o designer compreender gêneros e suas diferenças ao elaborar um produto, sendo essa prática tão necessária quanto o designer ter conhecimento de ergonomia, funcionalidade e estética (LIN, 2016).

Sendo a maior parcela dos consumidores do mundo, as mulheres não querem mais ser definidas por padrões estereotipados e patriarcais, pois acreditam que esses padrões as diminuem como humanas, chefes de família e mulheres (TREND WATCHING, 2015), assim, é possível notar a importancia de entender, identificar e mapear as diversidades de desejos, comportamentos e gostos desse grupo que há muito foi negligenciado e que hoje luta por seu reconhecimento, a fim de identificar as tendências e elaborar produtos que verdadeiramente conversem com a população (ZACARIAS, PEREIRA e MARTINS, 2016). 


\section{Design para Empoderar}

$\mathrm{O}$ design pode ser utilizado como uma arma de empoderamento tanto para quem o concebe quanto para aqueles que o consomem, sendo que, cabe ao designer, como agente social e formador e disseminador de opinião, conhecer bem o meio em que se encontra, para projetar de acordo com seus usuários, de forma genuína e não estereotipada.

Lupton (1993) em seu estudo sobre objetos de design e o público feminino afirma que os objetos não tem um significado estável que foi definido por seus criadores. Os objetos criam um significado de acordo com os costumes aos quais se associa, como ele é retratado na mídia e a definição dada pelas pessoas que o utiliza (LUPTON, 1997). Entretanto, a autora Henzel Clark (2009) assegura que, mesmo os objetos não tendo em si um significado definido, quando ele carrega consigo características que remetem a feminilidade, o produto acaba por portar uma associação implícita de trivialidade e passividade. Essa associação é dada devido a cultura patriarcal, e acaba por fazer com que o produto em si ajude na desvalorização da figura feminina.

Muito utilizado no design gráfico, marketing e publicidade, o design empoderador já é uma constante no dia-a-dia. Entretanto, esse tipo de design é ainda pouco utilizado quando se fala da vertente de produtos e com a finalidade de empoderar mulheres. Há, ainda hoje, poucas designers de produtos do sexo feminino conhecidas, sendo elas geralmente associadas a homens com quem trabalharam e/ou escolas que frequentaram. Com essa base, já é possível perceber que o campo do design de produto, durante muitos anos, foi pouco aberto às mulheres, e ainda hoje, há dificuldades em encontra-las em grandes empresas, desenvolvendo projetos para seu próprio sexo.

Segundo a designer e engenheira Yvone Lin (2016), 85\% dos produtos vendidos são feitos por homens, sendo que $85 \%$ das compras são realizadas por mulheres. A autora acredita que a insatisfação das mulheres face aos produtos existentes, dá-se pela diferença de gênero e mentalidade de quem o faz e de quem o consome, visto que é mais fácil fazer um produto ou serviço pensando em si próprio como público alvo, e adotando características que gostaria que tivessem em tal produto ou serviço.

Pesquisas sobre empoderamento em produtos evidenciam que a participação de pelo menos uma pessoa com as características do consumidor final durante todo o processo de elaboração do produto, acarreta em um produto final que agrada mais seus usuários e que se torna empoderador (LADNER, 2015).

O empoderamento feminino, hoje, é vendido como qualquer outro produto. Essa construção foi desenvolvida no pensamento dos consumidores durante muito tempo, tendo começado por volta dos anos 60, principalmente no âmbito publicitário. Em 1968, houve uma grande "explosão" dos cigarros Virginia Slim, que se tornou um produto empoderador para muitas mulheres, sendo um cigarro que promovia a independência do grupo (MACLARAN, 2012). Nesse ano, o publicitário Leo Burnett criou uma famosa campanha (Figura 1) para a marca de cigarros, com a finalidade de empoderar as mulheres e exaltar suas lutas, criou o slogan: "You've come a long way, baby" (MACLARAN, 2012). 


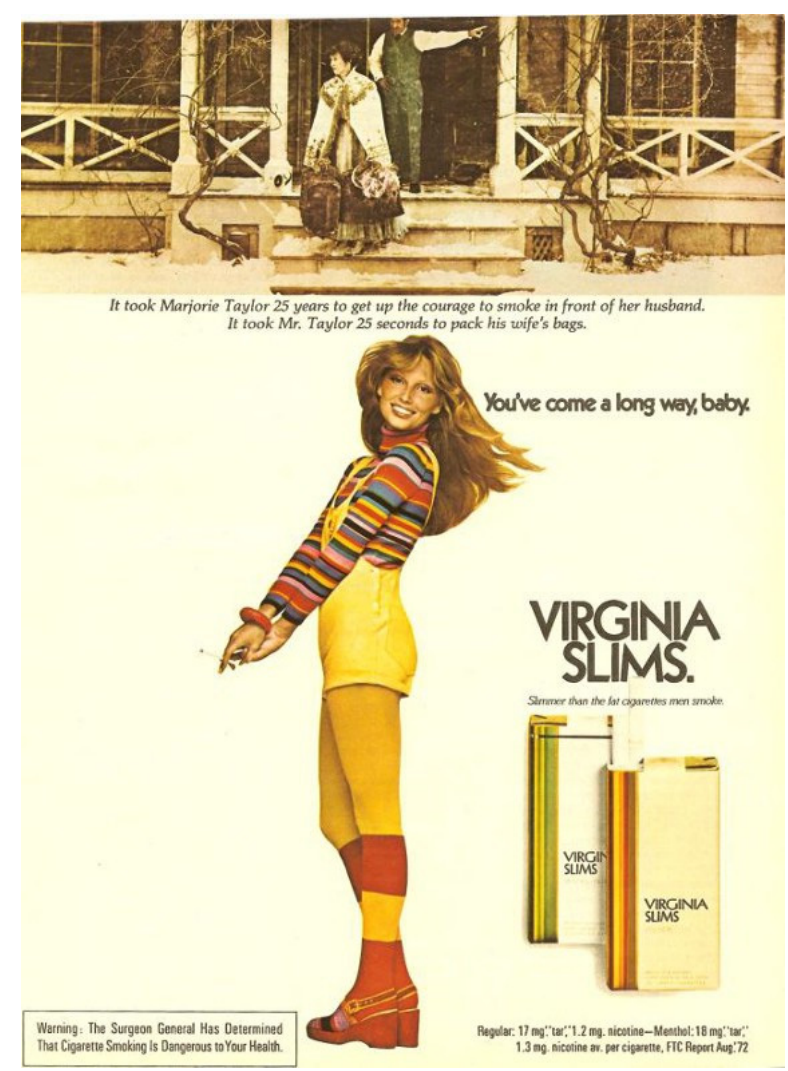

Figura 1: Propaganda Virginia Slims. Fonte: Cheek, 2018.

Com a chegada dos anos 90, a imagem do que a mulher considerava empoderador modificou. A terceira onda do feminismo trouxe consigo uma expansão do pensamento da mulher e maior independência. O desejo de empoderar-se e serem protagonistas de sua própria vida, marcou os anos que decorreram até a virada do século. Ser vítima da sociedade não era mais uma opção pera essas novas feministas, sendo assim, elas acreditavam que tudo a sua volta poderia ser empoderador se assim elas o quisessem (MACLARAN, 2012). Esse pensamento ajudou para que as propagandas e produtos de grandes empresas começassem a adotar uma nova postura mediante seu público alvo. Assim surgiram estratégias de vendas voltadas exatamente para o publico feminino, sendo que duas delas se descaram devido a seu alcance, gerando expressões próprias para designá-las, são elas: Commodity Feminism e Femvertising.

Os dois conceitos mencionados tratam-se especialmente de estratégias de marketing, sendo que o Commodity Feminism é um termo mais antigo e refere-se a estratégias publicitárias que algumas marcas utilizavam para desenvolverem valores ideológicos aos seus produtos, apropriando-se de discursos feministas para fins comerciais (SANTOS, 2016). Entretanto, Femvertisign chega como mais do que uma estratégia, mas um novo estilo de propaganda voltada para o publico feminino (HAMILIN; PETERS, 2018). A palavra que nasce da união de Feminism e Advertising, foi criada em 2014 pelo site She Knows, com a finalidade de mostrar como algumas marcas tornaram o empoderamento feminino como valor fundamental pelo qual a imagem do produto e da empresa se consolidam (HAMLIN \& PETERS, 2017).

O consumo feminino, com a chegada da terceira onda do feminismo modificou, e algumas empresas começaram a enxergar como sendo Mainstream, assim, propuseram que ele seria acessível a qualquer pessoa através do consumo, transformando-o em iconoclasta, divertido e acessível, de uma maneira que nunca havido sido antes do mercado (HAMLIN; PETERS, 2018).

Nota-se que o design como empoderador feminino teve sua maior difusão a partir da década de 90, ganhando bastante destaque a partir do ano de 2010, onde é possível ver como muitas das empresas começaram a apostar em propagandas que mostrava um mulher empoderada como forma de ganhar mais público. Esse é o caso do comercial Dream Crazier da Nike, onde mostra atletas, patrocinadas pela empresa, que quebraram barreiras, e narram um pouco de suas histórias visando 
mostrar que mesmo sendo estabelecido pela sociedade patriarcal que uma mulher não pode fazer determinada coisa, elas romperam padrões e são conhecidas mundialmente.

Em 2015 surge a Little Ms. Crate, um serviço de caixas de assinatura, criado pela KickStater uma empresa crowdfounded que visa incentivar meninas e mulheres a seguirem carreiras que não são consideradas "femininas". Essas carreiras englobam ciências, tecnologia, engenharia e matemática. A empresa criou um produto visando que as mulheres assinem a STEM Box (Figura 2), onde recebem mensalmente uma caixa em suas residências que contém livros e jogos para utilizarem de forma individual ou em grupo, sempre visando encorajar meninas e mulheres a se conectem mais com essas áreas de estudos e profissões (KICKSTARTER, 2016).
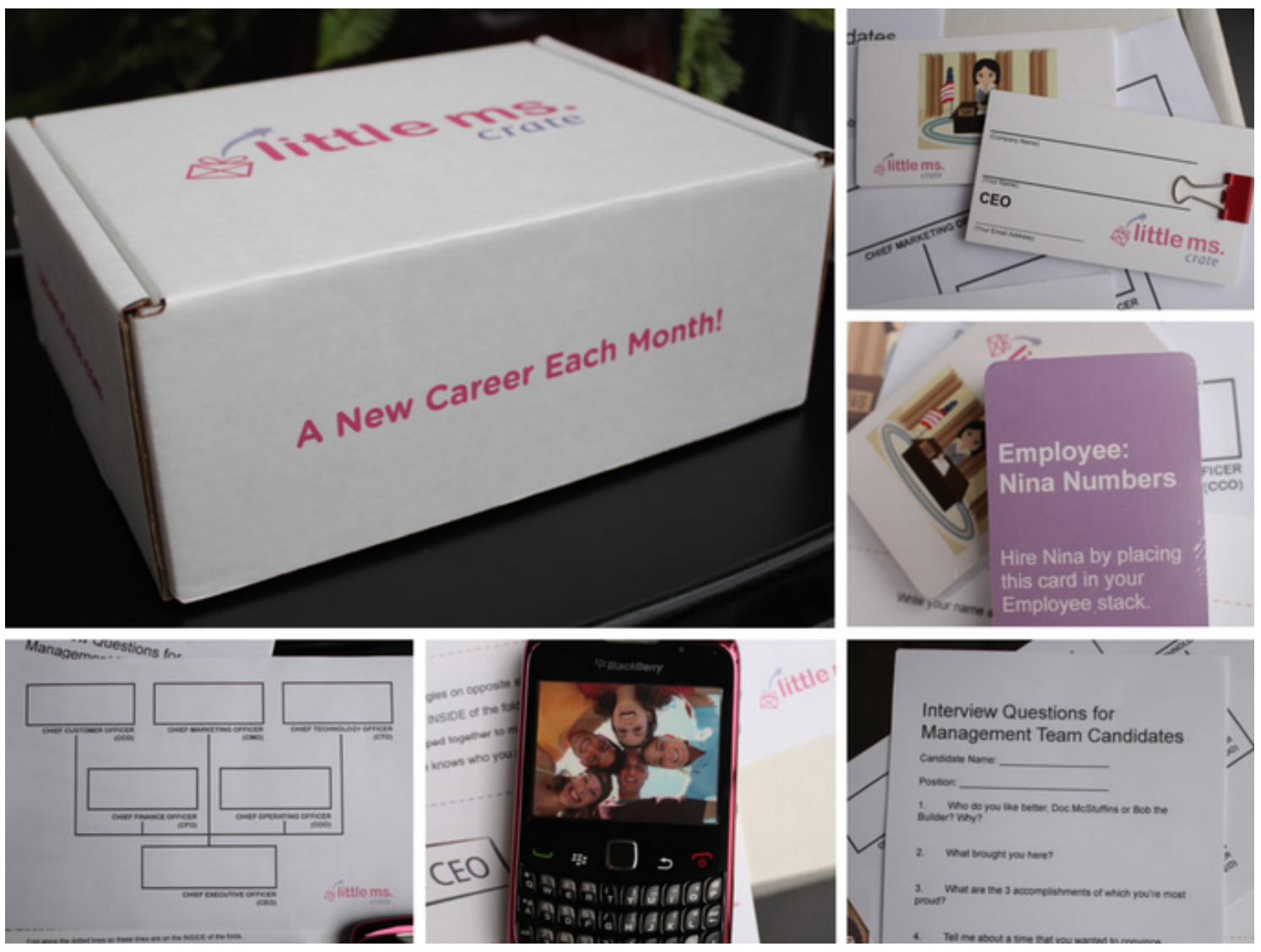

Figura 2: STEM Box. Fonte: Kickstrter, 2016

Outros casos de produtos empoderadores pode ser encontrado em vestuários feminino, onde muitas marcas utilizam da independência da mulher, feminismo e o poder por ela conquistado como o conceito para suas peças. Além de ser usado como conceito para peças de grandes marcas, o empoderamento feminino também é visto quando empresas como BeGirl, projetam peças de higiene íntima visando a maior liberdade da mulher (Figura 3), além de tentarem chegar nas casas com menor renda ao redor do mundo, provando as jovens que não devem se envergonhar de sua menstruação ou se privarem de algo (BeGirl). 


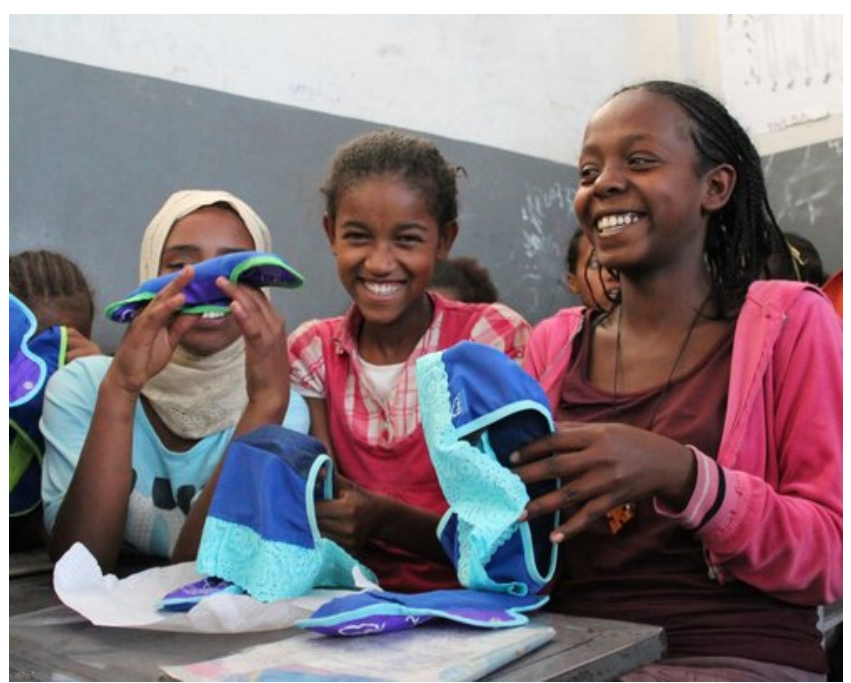

Figura 3: Calcinhas BeGirl. Fonte: BeGirl, [2015-2019].

O empoderamento feminino através do produto, como apontado por Maclaran (2012) teve maior alcance a partir dos anos 90, quando as mulheres, em grande parte, começaram a se apropriar de seus próprios desejos e não mais escondê-los a fim de não assustar os homens. Entretanto, ainda hoje, embora muito necessário, é difícil encontrar produtos que sejam abertamente empoderadores, sendo que propagandas, cartazes, estampas e até mesmo alguns sites, já conseguem o fazer e vender sem grandes esforços para alcançar esse público e empoderamento. Nota-se então certa dificuldade do designer de produto em assimilar essa tendência e torna-la parte integrante de seus projetos.

O design empoderador pode ser visto nas propagandas desde 1880 quando elas começaram a serem difundidas (LUPTON, 1997). Os publicitários, desde o início, tiveram muita consciência de seu público e procuraram sempre maneiras de cativá-lo, assim sendo, as propagandas feitas para o público feminino sempre teve a função de chamar a atenção das mulheres e dá-las, de alguma forma, mais poder e autonomia.

Mesmo quando as propagandas eram consideradas extremamente machistas, é possível notar que os publicitários, em sua maioria, eram assertivos ao "venderem" produtos, visto que sabiam desde o início que a mulher era a responsável por gerir a maior parcela de compras em uma família. Esse conhecimento, garantiu que a publicidade fosse a primeira a gerar empoderamento feminino, antes mesmo que os produtos dos quais ela falava soubesse do alto valor desse mercado.

Os produtos voltados para o público feminino têm suas primeiras aparições como tal, mais tarde do que a publicidade, por volta de 1920 (LUPTON, 1997). Percebendo o grande mercado que a publicidade já explorava, os designers começaram a projetar produtos para uso doméstico, a fim de "facilitar" a vida das donas de casa, que desde o final da revolução industrial eram as responsáveis por gerir o lar e o bem-estar da família, enquanto o homem era o provedor do dinheiro (LUPTON, 1997). Utensílios domésticos, produtos de limpeza e alimentação, começaram a servir como um meio de facilitar a vida da mulher, ajudando ela no cuidado do lar e filhos, que eram as funções reconhecidas das mulheres da época. Viu-se então máquinas de lavar tecnológicas, aspiradores de pó e torradeiras com formas aerodinâmicas e futuristas, que lembravam os carros que os maridos possuíam, além de telefones, que surgem como uma forma de manter as mulheres dentro de casa, mas ainda movimentando o mercado consumidor e fazendo a melhor propaganda dos produtos, a indicação para amigas (LUPTON, 1997).

Com o surgimento e a difusão dos movimentos feministas por todo o mundo, Maclaran (2012), aponta em seu estudo que os publicitários foram ágeis em melhorar seus trabalhos para que se encaixassem nessa nova perspectiva de consumidora. O marketing tentou entender da melhor forma os interesses e lutas dessa "nova mulher" e utilizar esses interesses como um meio de consumo, tentando empoderar a figura feminina e sua luta através de propagandas. Entretanto, essa verdade não se aplica também aos designers de produto, que mantiveram-se pensando na mulher como uma grande consumidora, entretanto apenas de produtos domésticos, cuidados do lar e da família e beleza. Essa visão durou por muitos anos na mente dos designers de produto, sendo ainda notada até os dias atuais, 
como por exemplo, em muitos carros que, segundo Yvonne Lin (2016), são feitos para homens e testados com percentis masculinos, o que acarreta em um maior risco de vida para as mulheres que os utilizam.

Segundo o Instituto de Pesquisa Patricia Galvão, o retrato de uma mulher independente e inteligente tem ganhado bastante espaço nas propagandas e produtos, e com isso, o empoderamento tem ficado cada dia mais em destaque e se tornado quase que uma obrigatoriedade na hora de projetos. Entretanto, as mulheres retratadas pelos designers e publicitários ainda seguem um padrão estético atrasado, o que pode causar um empoderamento incompleto, como se as lutas feministas lutassem apenas por mulheres magras, altas, heterosexuais e caucasianas.

\section{Conclusões}

A mulher já passou por muito para conquistar seu espaço social, político, acadêmico e como consumidora, mesmo que ainda falta muito a ser conquistado nesses setores. Entretanto as mulheres não toleram mais marcas e empresas que não a represente como sujeito, que não a reconhece quanto a seu valor como consumidora ativa e que quer ser representada de forma não estereotipada.

Como apontado por Safar e Dias (2014), os produtos de design são uma forma de reproduzir valores intangíveis à sociedade em que estão inseridos, sendo assim, o projetista necessita ter consciência dessa nova mulher e ajuda-la diariamente a conquistar seu lugar de direito na sociedade através dos produtos. Ao pensar dessa forma, o designer aumenta venda de produtos, se destaca no mercado e ainda garante um mundo mais igualitário.

Segundo o site de tendências internacional TrendWatching (2015), as mulheres procuram por marcas que se posicionem em relação à assuntos de seu interesse, como o sexismo, assim, criar produtos que mostrem o posicionamento de sua empresa e auxiliem as mulheres a garantirem seu espaço como sujeito empoderado que é, pode aumentar incrivelmente suas vendas e percepção no mercado.

Segundo Butler (2003), as mulheres querem ser representadas plenamente, e buscam emancipação das mesmas categorias das quais é reprimida por ser mulher. Assim, focando apenas no mercado consumidor, a mulher quer ser reconhecida como tal pelas empresas e empoderada por elas, ganhando autonomia suficiente para decidir seu próprio caminho sem estar vinculada a estereótipos ou a alguma figura masculina. Seguindo esse pensamento, é evidente a demanda social que o empoderamento traz, sendo que o designer, como ser social que é, necessita de sensibilidade para compreender esse público que tem as suas diferenças etnológicas, sociais, sexuais, mas que unem-se no ato de serem mulheres, e isso por si só já é muito a ser compreendido e associado à produtos sem estereótipos de gênero.

Beauvoir (2015) acredita que o corpo feminino dever ser a situação e instrumento de sua liberdade, logo, tudo que está a volta da mulher pode se tornar empoderador, se assim ela desejar, como é identificado por Maclaran (2012). Entretanto, criar produtos que catalisem o processo de empoderamento da mulher e a ajude a se emancipar de situações que muitas vezes podem ser consideradas constrangedoras e usar sua força para empoderar mais mulheres a sua volta, pode ser capaz de não apenas gerar uma boa publicidade para empresa e aumento de vendas, mas também uma sociedade menos reprimida e com valores culturais atualizados.

O empoderamento feminino, assim como o design é uma ferramenta social muito importante para a evolução da sociedade, sendo que, é dever do projetista avaliar o seu mercado de forma global e identificar as necessidades mais específicas da população. Essas necessidades têm que ser avaliadas segundo a ética e implantada de maneira a modificar o dia a dia do grupo estudado e promover uma relevância global.

Fazer produtos exige muita pesquisa, contato com usuários, testes de protótipos, e fazer um produto de sucesso envolve ainda um conhecimento avançado sobre as reais necessidades de seu público, uma imersão total no dia a dia do usuário e compreensão de suas dificuldades diárias quanto as pequenas adversidades enfrentadas por ele na sociedade. Pensar em um produto voltado para as mulheres de forma não estereotipada, por si só já é empoderador, visto que, a imagem de uma mulher livre de rótulos previamente postos, é a imagem de uma mulher empoderada e representada pelo o que realmente é como ser humano e consumidora.

Entender todo o processo e luta feminina para chegar onde estão hoje e serem vistas como o ser livre que é, é compreender também que as mulheres fazem parte efetiva do público consumidor e 
merecem respeito e compreensão dos designers. Merecem serem consideradas como mais do que um objeto de reprodução e cuidado do lar, tendo elas etnias, classe social, estudos, culturas e gostos diferentes, mas que são todas um ser a ser compreendido e tem necessidade de atenção por parte dos projetistas.

É evidente que as mulheres podem estar e fazer o que quiserem. Empoderar essas mulheres através de produtos de design, é trazer a tona uma vertente do design que há muito se escondia, uma vertente emancipadora, evoluída e inspiradora. É mostrar que produtos podem ser sim, mais do que apenas artigos para um fim único. Os produtos podem contribuir para a mudança da visão de mundo e evolução da sociedade, e o designer pode ser o agente da mudança, aquele que irá contribuir efetivamente para a melhora da sociedade.

\section{Product Design as a Tool for Female Empowerment}

\section{Abstract:}

This work intends to study how Product Design can contribute to Female Empowerment, verifying the concepts of empowerment and their relationship with design, the importance of women exercising their full citizenship today, ands discuss the role of design as a social agent. This study also highlights how design relates to the female consumer market, and which concerns the designer usually has in mind when creating a product for the female customer. In order to highlight the relationship between design and women's empowerment and show it is possible to create an empowering product, some case studies have been analyzed, which revealed that product design can be a very important social tool for the social development that women's empowerment brings.

Keywords: Design; Products; Empowerment; Feminism; Consumer

\section{Referências bibliográficas}

BEAUVOIR, Simone De. O Segundo Sexo. 2. ed. Lisboa: Quetzal, 2015.

BEGIRL. Be Girl. Disponível em: https://www.begirl.org/ [Acesso em jul. de 2020].

BUTLER, Judith. Problemas de género: feminismo e subversão da indentidade. 1.ed. Rio de Janeiro: Editora Civilização Brasileira, 2003.

CHEEK, Laura. The Impact of an Image: An Analysis of the Effect of a Female Model on Social Trends. Medium. Disponível em: https://medium.com/@lhc59549/the-impact-of-an-image-an-analysis-onthe-effect-of-a-female-model-on-social-trends-5c129dafab88 [Acesso em jun de 2020].

CLARK, Hazel; BRODY, David. Design Studies: A Reader. Bloomsbury, 2009.

CRUZ, M. H. S. Empoderamento das Mulheres. Inc.Soc, Brasília, v. 11, n. 2, p. 1, 2018.

FORNASIER, C. B. R., MARTINS, R. F. F. \& MERINO, E. Da Responsabilidade Social Imposta ao Design Social Movido pela Razão, 2012.

HAMLIN, C. \& PETERS, G. Consumindo como uma Garota: Subjetivação e Empoderamento na Publicidade Voltada para Mulheres. $\mathbf{1 8}^{\circ}$ Colóquio Brasileiro de Sociologia, 2017.

JOHNSON, Lisa; LEARNED, Andrea. Por que as mulheres compram?: Estratégias de Marketing para atingir um novo público. 1. ed. São Paulo: Futura, 2005.

KICKSTARTER. Little Ms. Crate. Kickstarter. Disponível em: https://www.kickstarter.com/projects/rcraig3/little-ms-crate/description [Acesso em jul. de 2020]. 
LADNER, Richard E. Design for User Empowerment. Interactions.AMC. University of Washington, 2015.

LIN, Y., 2016. The innovation economy is terrible at designing for women. Fast Company. Disponível em: https://www.fastcompany.com/3063442/the-innovation-economy-is-terrible-atdesigning-for-women [Acesso em 2020].

LUPTON, E. Mechanical Brides: Women and Machines from Home to Office. Nova York: Princeton Architectural Press, 1997.

MACLARAN, P. Marketing and Feminism in Historic Perspective. Journal of Historical Research in Marketing, v. 4, 2012.

NIEMEYER, L. Desing da Esperança: Design para Inovação Social, Caminhos a Seguir. Design \& Inovação Social, v. 2, 2017.

ONU. The World's Women: Trends and Statistics. Nova York, 2010.

PINTASILGO, M. D. L. Feminismo:: Palavra Velha?. Reflexão Cristã, Lisboa, v. 1, n. 26, p. 12-16, jan./1981.

SAFAR, G. \& ALMEIDA, M. G. Protagonismo Feminino no Design: um Resgate Histórico em Andamento. Em: Cadernos de Estudos Avançados em Design. Minas Gerais, 2014.

SAFAR, Giselle Hissa; DIAS, Maria Regina Alvares Correia. Estudos de gênero e seu impacto na história do design. Artigo publicado pelo UFES - Programa de Pós-Graduação em História. v.36 Minas Gerais, 2016.

SANTOS, L. D. d. Femvertising: o Empoderamento da Mulher na Propaganda sob a Ótica das Receptoras.. Trabalho de conclusão de curso para obtenção do grau de bacharel em comunicação social, 2016.

SILVA, G. J. D; NEVES, Maria Manuela. Design 3D em tecelagem jacquard como ferramenta para a concepção de novos produtos: aplicação em acessórios de moda. Universidade do Minho, Portugal, v. 1 , n. 1 , p. 1 , dez./2005.

STROMQUIST, Nelly. La búsqueda del empoderamiento: em qué puede contribuir el campo de la educación. Poder y Empoderamiento de las Mujeres, Colombia, p. 75-99, 1997.

TREND WATCHING;, 2015. (F)Empowerment. Disponível em:

http://trendwatching.com/trends/fempowerment/ [Acesso em Março 2018].

UNICEF. El marco conceptual de igualdad y empoderamiento de las mujeres. Poder y

Empoderamiento de las mujeres, Colombia, p. 173-187, 1997

WANDERLEY, M. L., ANDRADE, P. S., BARROS, R. Q. d. \& LINS JUNIOR, W. G. Bases Comuns do Design: Uma Discussão sobre o Impacto e Papel Social do Design. Design \& Complexidade. , 2017.

WOMEN CHOICE AWARD - The female powerhouse. Women's Choice Award, 2018.

ZACARIAS, L. C., PEREIRA, P. B. A. \& MARTINS, R. F. d. F. O Feminismo e o Fora-da-lei: Sinais de uma Tendência sob a Perspectiva Arqueotípica. Artigo para o $12^{\circ}$ Colóquio de moda, 2016. 